\title{
Electric and Magnetic Fields Predicted by Different Electromagnetic Models of the Lightning Return Stroke Versus Measured Fields
}

\author{
Yoshihiro Baba, Member, IEEE, and Vladimir A. Rakov, Fellow, IEEE
}

(Invited Paper)

\begin{abstract}
We have compared current distributions along a vertical lightning channel above flat ground excited at its bottom by a lumped current source and electromagnetic field waveforms at different distances from the channel, calculated using the finitedifference time-domain method, for different lightning returnstroke electromagnetic models. The channel representations considered include a vertical, perfectly conducting wire surrounded by air (type 1), a vertical wire in air loaded by additional distributed series inductance $L=2.5 \mu \mathrm{H} / \mathrm{m}$ and distributed series resistance $R=0.5 \Omega / \mathrm{m}$ (type 2 ), a vertical, perfectly conducting wire embedded in dielectric of relative permittivity $\varepsilon_{r}=4$ that occupies the entire half space (type 3 ), a vertical, perfectly conducting wire embedded in a 10-m-radius dielectric cylinder of $\varepsilon_{r}=400$ surrounded by air (type 4), and a vertical wire embedded in a 10-m-radius cylinder of $\varepsilon_{r}=5$ and relative permeability $\mu_{r}=5$ surrounded by air (type 5). For the type-1 model, the speed of the current wave propagating along the lightning channel is essentially equal to the speed of light, $v=c$. For type-2, type-3, and type-5 models, $v=0.5 c$, and for the type- 4 model, $v=0.7 c$. Models of types 2 and 5 reproduce the maximum number of characteristic features of electric and magnetic field waveforms observed at distances ranging from 1 to $200 \mathrm{~km}$ from natural lightning and at distances ranging from tens to hundreds of meters from rockettriggered lightning. Modifications of type- 2 and type-5 models in which distributed channel resistance is not uniform can reproduce all five characteristic features. The influence of lossy ground with conductivity as low as $0.1 \mathrm{mS} / \mathrm{m}$ on vertical electric and azimuthal magnetic fields within about $d=5 \mathrm{~km}$ is not significant. The initial peak of vertical electric field at $d=50 \mathrm{~km}$ for $\sigma=0.1 \mathrm{mS} / \mathrm{m}$ is $20 \%$ smaller than that for $\sigma=\infty$. The $10 \%-90 \%$ rise time at $d=50 \mathrm{~km}$ is $5 \mu \mathrm{s}$ for $\sigma=0.1 \mathrm{mS} / \mathrm{m}$ versus $1 \mu \mathrm{s}$ for $\sigma=\infty$.
\end{abstract}

Index Terms-Electromagnetic model, lightning, lightning current, lightning electromagnetic field, lightning return stroke.

\section{INTRODUCTION}

$\mathbf{L}$ IGHTNING return-stroke models are needed in studying lightning effects on various objects and systems, and in characterizing the lightning electromagnetic environment.

Manuscript received October 3, 2008; revised February 19, 2009. First published June 2, 2009; current version published August 21, 2009. This work was supported in part by the Ministry of Education, Culture, Sports, Science and Technology (MEXT) under Grant 18760220 and in part by the National Science Foundation under Grant ATM-0346164.

Y. Baba is with the Department of Electrical Engineering, Doshisha University, Kyoto 610-0321, Japan (e-mail: ybaba@mail.doshisha.ac.jp).

V. A. Rakov is with the Department of Electrical and Computer Engineering, University of Florida, Gainesville, FL 32611 USA (e-mail: rakov@ ece.ufl.edu).

Color versions of one or more of the figures in this paper are available online at http://ieeexplore.ieee.org.

Digital Object Identifier 10.1109/TEMC.2009.2019122
Rakov and Uman [1], based on governing equations, have categorized return-stroke models into four classes: gas dynamic models [2], electromagnetic (EM) models [3], distributedcircuit models [4], [5], and "engineering" models [6]. Only EM models are considered in this paper.

EM return-stroke models are relatively new, and in studying lightning electromagnetic interaction with various systems, they are the most rigorous models suitable for specifying the source. In these models, Maxwell's equations are solved to yield the distribution of current along the lightning channel using numerical techniques, such as the method of moments (MoM) [7], [8] or the finite-difference method [9]. In contrast to distributed-circuit and engineering models, EM models allow a self-consistent fullwave solution for both the current distribution along the lightning channel and the associated EM fields. This class of models has attracted considerable attention during the last ten years or so (see recent reviews by Baba and Rakov [3], [10]). EM models have been reviewed in [3] with an emphasis on the lightning channel representation, excitation method, and numerical procedure for solving Maxwell's equations, and in [10] with an emphasis on their applications.

In this paper, we present vertical electric and azimuthal magnetic field waveforms predicted by different electromagnetic return-stroke models at different distances from the channel, calculated using the finite-difference time-domain (FDTD) method [9] in the 2-D cylindrical coordinate system, and compare model predictions with measurements. The influence on EM field waveforms of nonuniformly distributed channel resistance, which controls the variation of attenuation of current along the lightning channel, and lossy ground is also investigated. Note that for the same computer memory, the use of 2-D cylindrical FDTD method allows one to considerably increase the range of distances at which fields can be computed compared to the 3-D FDTD method.

\section{REPRESENTATION OF THE LIGHTNING RETURN-STROKE CHANNEL IN ELECTROMAGNETIC MODELS}

There are six types of channel representation used in electromagnetic models:

1) a perfectly conducting/resistive wire in air above ground [11];

2) a wire loaded by additional distributed series inductance in air above ground [12]; 
3) a wire surrounded by a dielectric medium (other than air) that occupies the entire half space above ground (the artificial dielectric medium is used only for finding current distribution along the lightning channel, which is then removed for calculating EM fields in air) [13];

4) a wire coated by a dielectric material in air above ground [14];

5) a wire coated by a fictitious material having high relative permittivity and high relative permeability in air above ground [15];

6) two parallel wires having additional distributed shunt capacitance in air (this fictitious configuration is used only for finding current distribution, which is then applied to a vertical wire in air above ground for calculating electromagnetic fields) [16].

In the following, we will review the return-stroke speed and channel characteristic impedance corresponding to each of the six types of channel representation. The return-stroke speed, along with the current peak, largely determines the radiation field initial peak [17], while the characteristic impedance of the lightning channel influences the magnitude of lightning current and/or the current reflection coefficient at the top of the strike object when a lumped voltage source is employed. It is desirable that:

1) typical values of return-stroke speed are in the range from $c / 3$ to $c / 2$ [18], as observed using optical techniques, where $c$ is the speed of light;

2) the equivalent impedance of the lightning return-stroke channel is expected to be in the range from 0.6 to $2.5 \mathrm{k} \Omega$ [19].

Type 1: The speed of the current wave propagating along a vertical, perfectly conducting/resistive wire is nearly equal to the speed of light, which is two to three times larger than typical measured values of return-stroke wavefront speed $(c / 3-$ $c / 2$ ). This discrepancy is the main deficiency of type-1 models. The characteristic impedance of the channel-representing vertical wire of radius $3 \mathrm{~cm}$ is estimated to be around $0.6 \mathrm{k} \Omega$ at a height of $500 \mathrm{~m}$ above ground (it varies with height above ground). This is right at the lower bound of its expected range of variation $(0.6-2.5 \mathrm{k} \Omega$ ). Note that a current wave suffers attenuation (dispersion) as it propagates along a vertical wire even if it has no ohmic losses [20]. Further attenuation can be achieved by loading the wire by distributed series resistance.

Type 2: The speed of the current wave propagating along a vertical wire loaded by additional distributed series inductance of 17 and $6.3 \mu \mathrm{H} / \mathrm{m}$ in air is $c / 3$ and $c / 2$, respectively, if the natural inductance of vertical wire is assumed to be $L_{0}=2.1 \mu \mathrm{H} / \mathrm{m}$ (as estimated by Rakov [21]) for a 3-cmradius wire at a height of $500 \mathrm{~m}$ above ground). The corresponding characteristic impedance ranges from 1.2 to $1.8 \mathrm{k} \Omega$ $\left(0.6 \mathrm{k} \Omega \times[(17+2.1) / 2.1]^{1 / 2}=1.8 \mathrm{k} \Omega\right.$, and $0.6 \mathrm{k} \Omega \times[(6.3+$ $2.1) / 2.1]^{1 / 2}=1.2 \mathrm{k} \Omega$ ) for the speed ranging from $c / 3$ to $c / 2$. The characteristic impedance of the inductance-loaded wire is within the range of values of the expected equivalent impedance of the lightning return-stroke channel. Note that additional inductance has no physical meaning and is invoked only to reduce the speed of current wave propagating along the wire to a value lower than the speed of light. The use of this representation allows one to calculate both the distribution of current along the channel-representing wire and remote electromagnetic fields in a single, self-consistent procedure. Note that Bonyadi-Ram et al. [22] have recently incorporated additional distributed series inductance that increases with increasing height in order to simulate the optically observed reduction in return-stroke speed with increasing height [23].

Type 3: For a vertical wire surrounded by a dielectric medium of relative permittivity greater than 1, occupying the entire half space above flat ground, the speed of the current wave is lower than $c$. When the relative permittivity is 9 or 4 , the speed is $c / 3$ or $c / 2$, respectively. The corresponding characteristic impedance ranges from 0.2 to $0.3 \mathrm{k} \Omega(0.6 \mathrm{k} \Omega / \sqrt{9}=0.2 \mathrm{k} \Omega$, and 0.6 $\mathrm{k} \Omega / \sqrt{4}=0.3 \mathrm{k} \Omega$ ) for the speed ranging from $c / 3$ to $c / 2$. These characteristic impedance values are smaller than the expected ones $(0.6-2.5 \mathrm{k} \Omega$ ). Moini et al. [13] used a relative permittivity value of 5.3 to set the wave propagation speed at $0.43 c$.

Type 4: Kato et al. [14] represented the lightning channel by a vertical, perfectly conducting wire, which had a radius of 1 $\mathrm{cm}$ and was placed along the axis of a 4-m-radius dielectric cylinder of relative permittivity 200 . This dielectric cylinder was surrounded by air. The speed of the current wave propagating along the wire was about $0.7 c$. Such a representation allows one to calculate both the distribution of current along the wire and the remote electromagnetic fields in a single, selfconsistent procedure, while that of a vertical wire surrounded by an artificial dielectric medium occupying the entire half space (type 3 described before) requires two steps to achieve the same objective. However, the electromagnetic fields produced by a dielectric-coated wire in air (type 4) might be influenced by the presence of coating.

Type 5: Miyazaki and Ishii [15] represented the lightning channel by a vertical wire, which was placed along the axis of a cylindrical or parallelepiped-shaped block having high relative permittivity and high relative permeability (transverse dimensions of the block, and the values of relative permittivity and permeability were not given in [15]). This structure was surrounded by air. The speed of the current wave propagating along the wire was about $0.5 c$. Similarly to type 4 , this representation allows one to calculate both the distribution of current along the wire and the remote electromagnetic fields in a single, self-consistent procedure. For the same speed of current wave, the characteristic impedance value for this channel representation is higher than that for type 4 , since both relative permittivity and permeability are set at higher values in type-5 model.

Type 6: The speed of the current wave propagating along two parallel wires having additional distributed shunt capacitance in air is $0.43 c$ when the additional capacitance is $50 \mathrm{pF} / \mathrm{m}$ [16]. In this model, each of the wires has a radius of $2 \mathrm{~cm}$, and the separation between the wires is $30 \mathrm{~m}$. Similar to type 3 described before, type 6 employs a fictitious configuration for finding a reasonable distribution of current along the lightning channel, and then, this current distribution is applied to the actual configuration (vertical wire in air above ground). Type 6 is not further considered in this paper. 

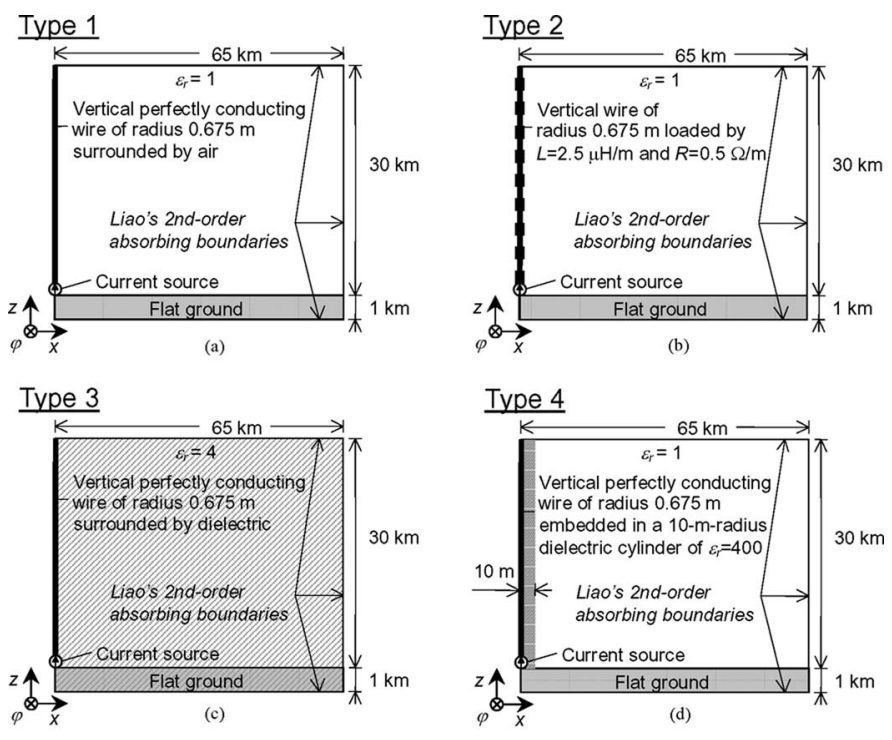

Type 5

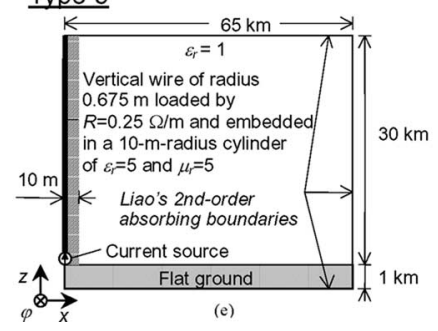

Fig. 1. Five representations of the lightning return-stroke channel excited at its bottom by a 10-m current source above flat, perfectly conducting ground, to be analyzed using the 2-D cylindrical FDTD method. (a) Vertical, perfectly conducting wire surrounded by air (type 1). (b) Vertical wire loaded by additional distributed series inductance $L=2.5 \mu \mathrm{H} / \mathrm{m}$ and distributed series resistance $R=0.5 \Omega / \mathrm{m}$ in air (type 2). (c) Vertical, perfectly conducting wire embedded in dielectric of $\varepsilon_{r}=4$, which occupies the entire half space (type 3). (d) Vertical, perfectly conducting wire embedded in a 10-m-radius dielectric cylinder of $\varepsilon_{r}=$ 400 surrounded by air (type 4). (e) Vertical wire embedded in a 10-m-radius cylinder of $\varepsilon_{r}=5$ and $\mu_{r}=5$ surrounded by air (type 5). For representation (a), $v=c$, for representations (b), (c), and (e), $v=0.5 c$, and for representation (d), $v=0.7 c$

\section{CURRENT Distributions FOR DifFERENT ELECTROMAGNETIC MODELS}

In this section, we present current distributions along a vertical channel above perfectly conducting ground excited at its bottom by a lumped current source that are predicted by the EM models of types 1-5, as described in Section II.

The five representations of a lightning channel excited at its bottom above flat, perfectly conducting ground, to be analyzed using the FDTD method in the 2-D cylindrical coordinate system, are illustrated in Fig. 1. Fig. 1(a) shows a vertical, perfectly conducting wire in air (type 1). Fig. 1(b) shows a vertical wire in air loaded by additional distributed series inductance $L=$ $2.5 \mu \mathrm{H} / \mathrm{m}$ and distributed series resistance $R=0.5 \Omega / \mathrm{m}$ (type 2 ). Note that the $0.5-\Omega / \mathrm{m}$ resistance is needed to stabilize highfrequency oscillations that appear when the $2.5-\mu \mathrm{H} / \mathrm{m}$ series distributed inductance is added. Distributed series resistance can also be used to control the attenuation of current wave propagating along the channel-representing wire. Fig. 1(c) shows a vertical, perfectly conducting wire embedded in a dielectric of $\varepsilon_{r}=4$, which occupies the entire half space (type 3 ). Fig. 1(d) shows a vertical, perfectly conducting wire embedded in a 10 -m-radius dielectric cylinder of $\varepsilon_{r}=400$ surrounded by air (type 4). Fig. 1(e) shows a vertical wire embedded in a 10-m-radius cylinder of $\varepsilon_{r}=5$ and $\mu_{r}=5$ surrounded by air (type 5). Although it is not expected for the vertical lightning channel to extend above $7.5 \mathrm{~km}$, the length of the channelrepresenting wire is set to $30 \mathrm{~km}$. This unrealistically long wire is employed to avoid effects of any reflections from the upper end of the channel in field waveforms during at least the first $100 \mu \mathrm{s}(=30 \mathrm{~km} / v$ for $v=c)$. Influence of channel length on model-predicted electric and magnetic fields will be discussed in Section IV. We will show that only distant $(d=50 \mathrm{~km})$ fields are significantly influenced by channel sections above $7.5 \mathrm{~km}$.

The lumped current source located at the bottom of each vertical wire shown in Fig. 1 has a length of $10 \mathrm{~m}$ (due to the cell size employed: height $10 \mathrm{~m}$ and width $5 \mathrm{~m}$ ), and produces a current waveform having a peak of $11 \mathrm{kA}$, a 10\%-90\% rise time (RT) of $1 \mu \mathrm{s}$, and a time to half value of $30 \mu \mathrm{s}$ (see the waveform labeled " $z^{\prime}=0$ " in Fig. 2). This channel-base current waveform is the same as the waveform, proposed by Nucci et al. [6] and thought to be typical for subsequent lightning return strokes, except for its rising portion ( $\mathrm{RT}=1 \mu \mathrm{s}$ versus $0.15 \mu \mathrm{s}$ in [6]). The rise time $\mathrm{RT}=1 \mu \mathrm{s}$ is comparable to typical values observed for subsequent return strokes [24]. For the FDTD calculations, the vertical conducting wire is represented by a zero-radius wire placed at the left-side boundary $(r=0)$ in the working space of $65 \mathrm{~km} \times 31 \mathrm{~km}$, which is divided into $5 \mathrm{~m} \times 10 \mathrm{~m}$ rectangular cells. When cells having a lateral side length of $5 \mathrm{~m}$ are used, the vertical $(z$-directed) zero-radius perfectly conducting wire placed at $x=0$ has an equivalent radius of $0.675 \mathrm{~m}=0.135 \times$ $5 \mathrm{~m}$ [25]. The cell size $(5 \mathrm{~m} \times 10 \mathrm{~m})$, and the current-source length $(10 \mathrm{~m})$ seem to be too large for calculating fields at $50 \mathrm{~m}$ ( 10 cells away from the source). However, we have verified that FDTD-calculated (for the same spatial discretization) field waveforms at a horizontal distance of $50 \mathrm{~m}$ for the engineering transmission-line model with $v=c$ agree with the corresponding waveforms calculated using the exact analytical equation [26] (not shown in this paper). Liao's second-order absorbing boundaries [27] are set at the bottom, top, and rightside boundaries in order to avoid reflections there. The time increment is set to $10 \mathrm{~ns}$.

Fig. 2 shows FDTD-calculated distributions of current along the lightning return-stroke channel for the different representations shown in Fig. 1. Fig. 2(a) shows that the current wave propagates along the perfectly conducting wire in air at the speed of light $(v=c)$. Fig. 2(b) shows that the current wave propagates along the conducting wire loaded by additional distributed series inductance $L=2.5 \mu \mathrm{H} / \mathrm{m}$ in air at speed $v=0.5 c$. Fig. 2(c) shows that the current wave propagates along the perfectly conducting wire surrounded by dielectric of $\varepsilon_{r}=4$ at speed $v=$ $0.5 c$. Fig. 2(d) shows that the current wave propagates along the perfectly conducting wire embedded in the 10-m-radius dielectric cylinder of $\varepsilon_{r}=400$ surrounded by air at speed $v=0.7 \mathrm{c}$. Fig. 2(e) shows that the current wave propagates along the conducting wire embedded in the 10-m-radius cylinder of $\varepsilon_{r}=5$ 


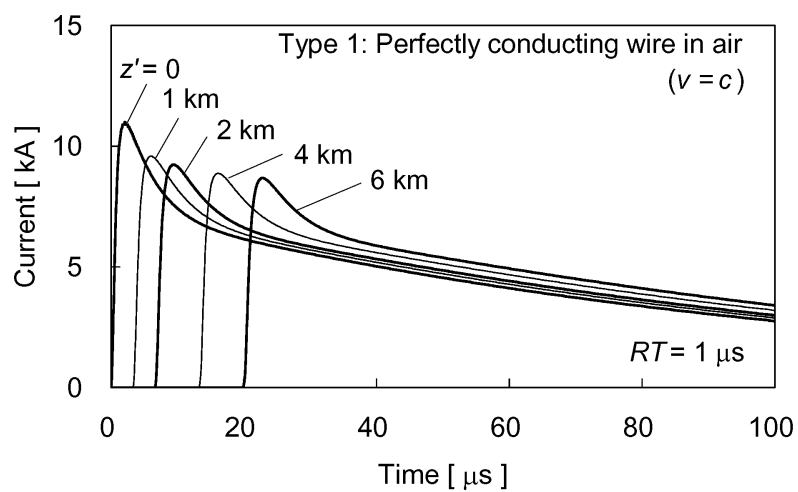

(a)

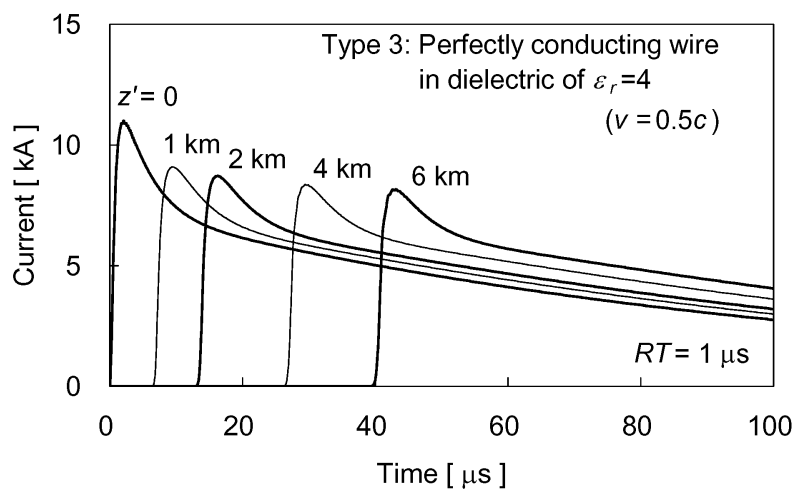

(c)

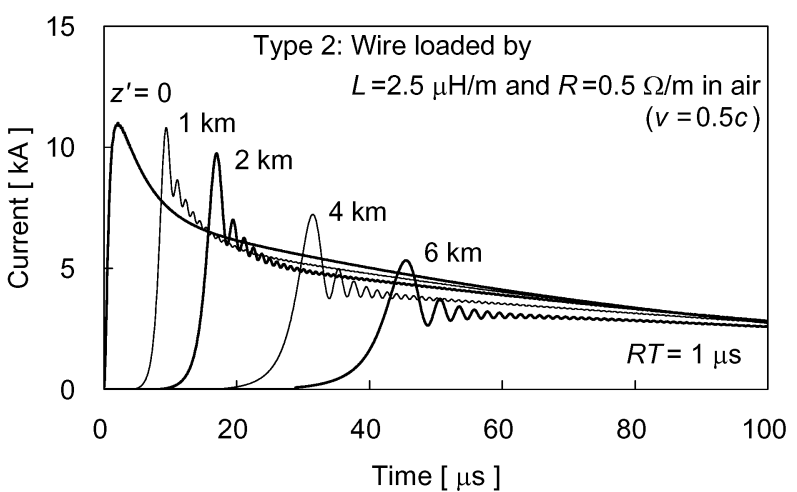

(b)

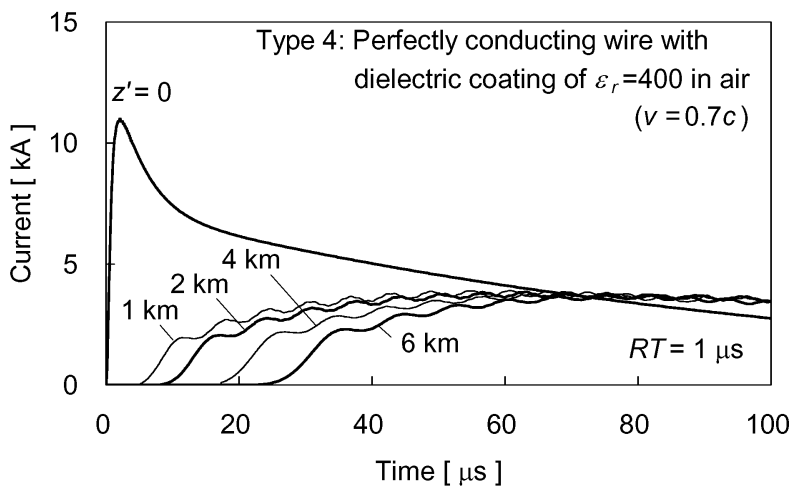

(d)

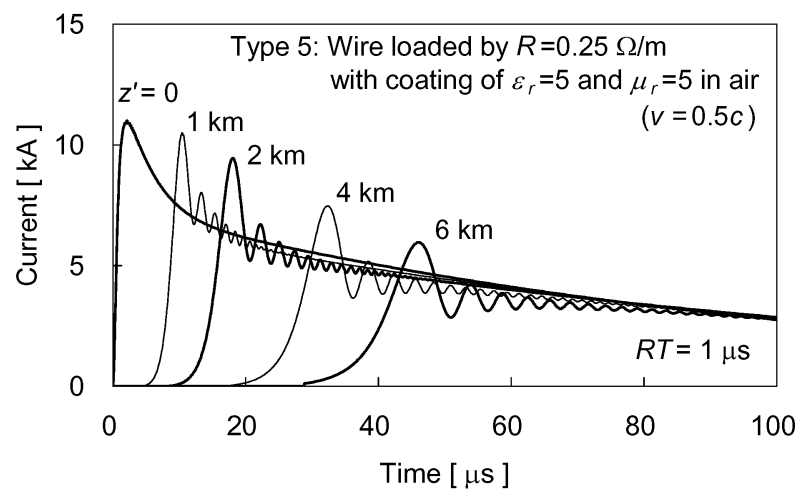

(e)

Fig. 2. Current waveforms at different heights calculated using the FDTD method for five representations of the lightning return-stroke channel shown in Fig. 1. (a) Type 1. (b) Type 2. (c) Type 3. (d) Type 4. (e) Type 5.

and $\mu_{r}=5$ surrounded by air at speed $v=0.5 c$. Note that these speeds were calculated based on times needed for current waves to propagate from $z^{\prime}=0$ to $2 \mathrm{~km}$ along a vertical wire, which were determined by tracking an intersection point between a straight line passing through $10 \%-90 \%$ points on the rising part of the current waveform and the time axis. In Fig. 2(b), (c), and (e), parameters of channel representation were adjusted to achieve the same value of $v=0.5 c$.

It appears from Fig. 2(d) that in order to reduce the speed of the current wave propagating along a vertical wire having a dielectric coating (type 4), which is surrounded by air, to a value similar to the typical measured return-stroke speed [18], the relative permittivity of the dielectric coating would need to be set to a very high value (much higher than in the case of dielectric half space). The current-wave propagation speed decreases with increasing thickness of the dielectric coating and with increasing its relative permittivity, but the dependence is weak [3]. The initial peak of the longitudinal current decays significantly owing to the presence of the dielectric coating having very high relative permittivity. It follows from comparison of Fig. 2(d) and Fig. 2(e) that increasing both the relative permittivity and relative permeability of the coating is more efficient in reducing the current-wave propagation speed than increasing the relative permittivity only. 


\section{E-field at $d=50 \mathrm{~m}$}

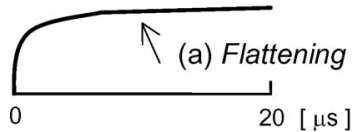

E-field at $d=5 \mathbf{~ k m}$

(b) Initial peak

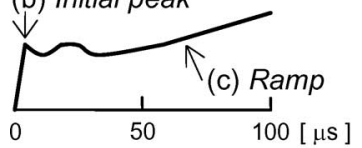

E-field at $d=50 \mathrm{~km}$

(b) Initial peak

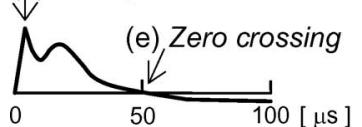

$\mathrm{H}$-field at $d=5 \mathrm{~km}$

(b) Initial peak

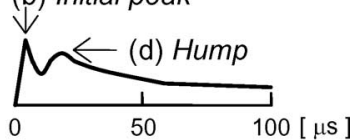

$\mathrm{H}$-field at $d=50 \mathrm{~km}$

(b) Initial peak

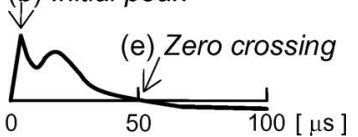

Fig. 3. Typical features of vertical electric and azimuthal magnetic field waveforms measured at different distances from lightning return strokes [1].

\section{COMPARISON OF MODEL-PREDICTED ELECTRIC AND MAGNETIC FiELDS With TyPICAL MEASUREMENTS}

In this section, we compare vertical electric and azimuthal magnetic field waveforms, calculated using the FDTD method for different channel representations and channel-base current waveform expected for subsequent return strokes $(\mathrm{RT}=1 \mu \mathrm{s})$, with typical measured electric and magnetic field waveforms due to natural lightning return strokes at distances $d=5$ and $50 \mathrm{~km}$ and triggered lightning strokes at $d=50 \mathrm{~m}$.

The following five features, as shown in Fig. 3, have been identified in electric and magnetic field waveforms measured at distances ranging from 1 to $200 \mathrm{~km}$ from natural lightning return strokes [28], and at tens to hundreds of meters from triggered lightning strokes [29]. These features have been used as benchmarks in testing the validity of various lightning returnstroke models [1]:

1) characteristic flattening of vertical electric field at tens to hundreds of meters within $15 \mu$ s or so of the beginning of return stroke;

2) sharp initial peak in both electric and magnetic field waveforms at a few kilometers and beyond;

3) slow ramp following the initial peak in electric field waveforms measured within few tens of kilometers;

4) hump following the initial peak in magnetic field waveforms measured within several tens of kilometers;

5) zero-crossing within tens of microseconds in both electric and magnetic field waveforms measured at $50-200 \mathrm{~km}$.

Fig. 4(a)-(c) shows vertical electric field waveforms at $d=$ $50 \mathrm{~m}, 5 \mathrm{~km}$, and $50 \mathrm{~km}$, calculated using the FDTD method for different representations of the 30-km-long lightning returnstroke channels shown in Fig. 1 (types 1-5). Fig. 4(d) shows FDTD-calculated waveforms of the azimuthal magnetic field at $d=5 \mathrm{~km}$. Fig. 4(a)-(d) also shows waveforms calculated for the type- 2 model and a shorter channel whose length is $7.5 \mathrm{~km}$ and whose upper end is connected directly to the absorbing boundary (no reflection). This 7.5-km-long channel has

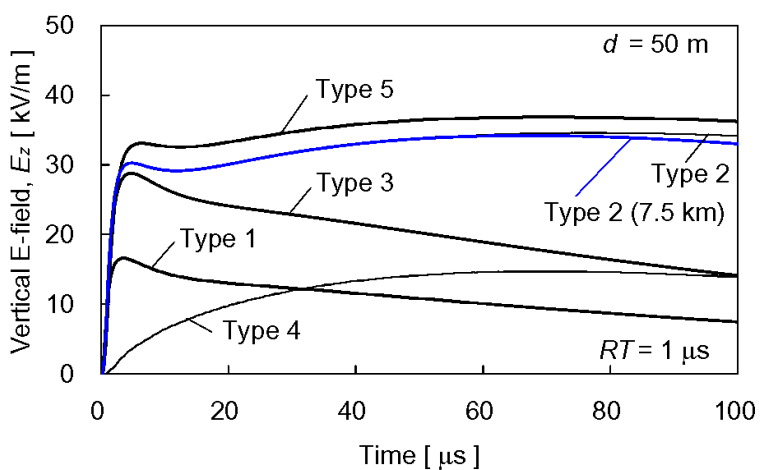

(a)

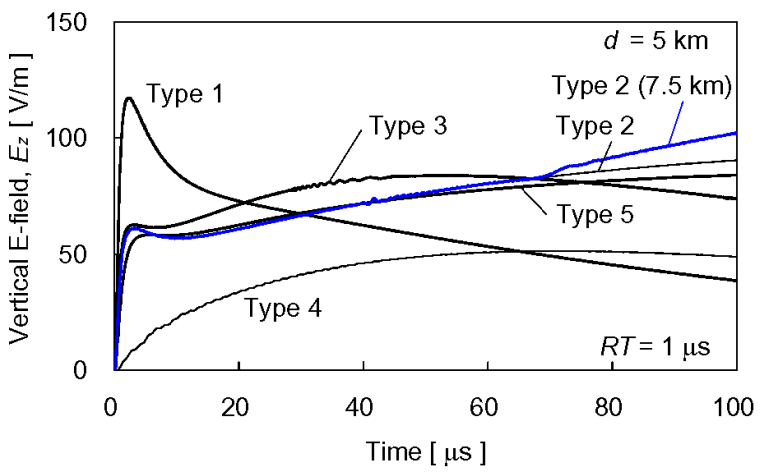

(b)

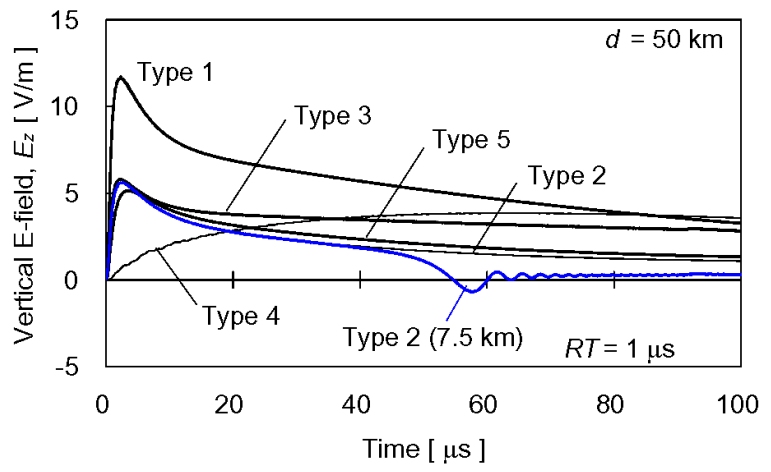

(c)

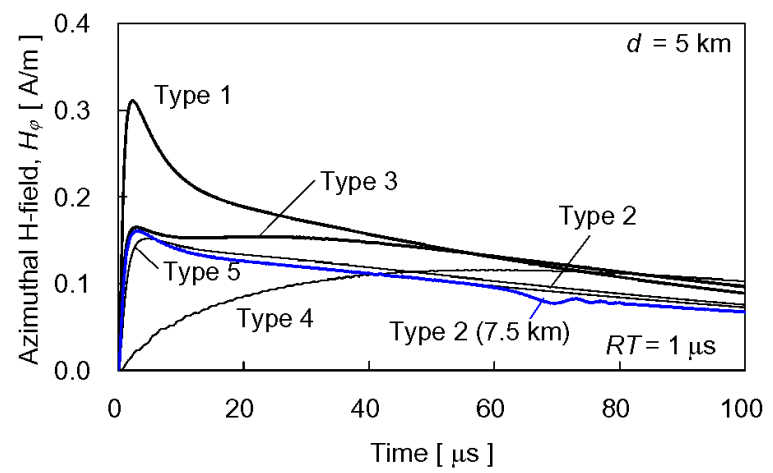

(d)

Fig. 4. Vertical electric field waveforms at (a) $d=50 \mathrm{~m}$, (b) $d=5 \mathrm{~km}$, and (c) $d=50 \mathrm{~km}$, and (d) azimuthal magnetic field waveforms at $d=5 \mathrm{~km}$, calculated using the FDTD method for different representations of the 30-kmlong lightning return-stroke channel shown in Fig. 1 (types 1-5). Also shown are waveforms calculated for the type- 2 model and a shorter channel whose length is $7.5 \mathrm{~km}$ and whose upper end is connected directly to the absorbing boundary. 
the same current distribution below $7.5 \mathrm{~km}$ as the $30-\mathrm{km}$-long channel. It is, therefore, expected that comparison of fields calculated for these different channel lengths, $7.5 \mathrm{~km}$ and $30 \mathrm{~km}$, will show the contribution of the unrealistic channel section above $7.5 \mathrm{~km}$.

Feature 1) is reproduced by type- 2 and type- 5 models. Although the effect of the channel section above $7.5 \mathrm{~km}$ is discernible after about $70 \mu \mathrm{s}$ in Fig. 4(a) $\left(E_{z}\right.$ at $\left.d=50 \mathrm{~m}\right)$, it is not significant. Feature 2) is reproduced by all model types considered, except for type 4 . Feature 3 ) is reproduced by type2 and type- 5 models. The effect of the channel section above $7.5 \mathrm{~km}$ is discernible after about $65 \mu$ s in Fig. 4(b) $\left(E_{z}\right.$ at $d=$ $5 \mathrm{~km}$ ): the ramp becomes steeper for the $7.5-\mathrm{km}$-long channel. Feature 4 ) is not reproduced by any model considered [see Fig. 4(d)]. The effect of the channel section above $7.5 \mathrm{~km}$ is discernible after about $65 \mu \mathrm{s}$ in Fig. $4(\mathrm{~d})\left(H_{\varphi}\right.$ at $\left.d=5 \mathrm{~km}\right)$ : $H_{\varphi}$ becomes smaller after $65 \mu$ s for the 7.5 -km-long channel. Feature 5) is not reproduced for channel length equal to $30 \mathrm{~km}$ by any model considered either. When the $7.5-\mathrm{km}$-long channel is employed, this feature is reproduced by the type- 2 model around $50 \mu$ s [see Fig. 4(c)]. Overall, it follows that fields predicted by type- 2 and type- 5 models better match experimental data than those predicted by any other model considered here. Note that the unrealistically long channel employed in this study influences distant $(d=50 \mathrm{~km})$ electromagnetic field waveforms significantly.

\section{MODIFICATION OF TYPE-2 AND TYPE-5 MODELS TO INCLUDE NONUNIFORMLY DISTRIBUTED CHANNEL RESISTANCE}

It follows from the electromagnetic field calculations in the preceding section that no EM model with the input parameters considered can reproduce either feature 4), the hump of the magnetic field, or feature 5), the zero-crossing of the remote fields. Baba et al. [30] have shown, using their engineering return-stroke model, that significant attenuation within a few tens of meters of the return-stroke channel base is needed to reproduce feature 4), and appreciable attenuation along the upper part (above about $7 \mathrm{~km}$ ) of the channel is needed to reproduce feature 5). Note that Thottappillil et al. [31] have shown that the traveling current source and Diendorfer-Uman models with a somewhat different channel-base current waveform whose time to half peak value is $20 \mu$ s reproduce features 2)-5). Further, Cooray et al. [32] have found that a horizontal section of the channel inside the cloud may be responsible for the observed zero-crossing in distant fields.

In this section, we calculate vertical electric and azimuthal magnetic field waveforms at $d=50 \mathrm{~m}, 5 \mathrm{~km}$, and $50 \mathrm{~km}$ from the lightning channel using the most promising type-2 and type-5 models that are modified here to include nonuniformly distributed series resistance. The modified type- 2 model has nonuniformly distributed series resistance: $R=2 \Omega / \mathrm{m}$ for $z^{\prime}=0-0.5 \mathrm{~km}, 0.65 \Omega / \mathrm{m}$ for $z^{\prime}=0.5-4 \mathrm{~km}, 1 \Omega / \mathrm{m}$ for $z^{\prime}=$ $4-7.5 \mathrm{~km}$, and $10 \Omega / \mathrm{m}$ for $z^{\prime}>7.5 \mathrm{~km}$. The modified type5 model has nonuniformly distributed series resistance: $R=$ $1 \Omega / \mathrm{m}$ for $z^{\prime}=0-0.5 \mathrm{~km}, 0.3 \Omega / \mathrm{m}$ for $z^{\prime}=0.5-4 \mathrm{~km}, 0.5 \Omega / \mathrm{m}$

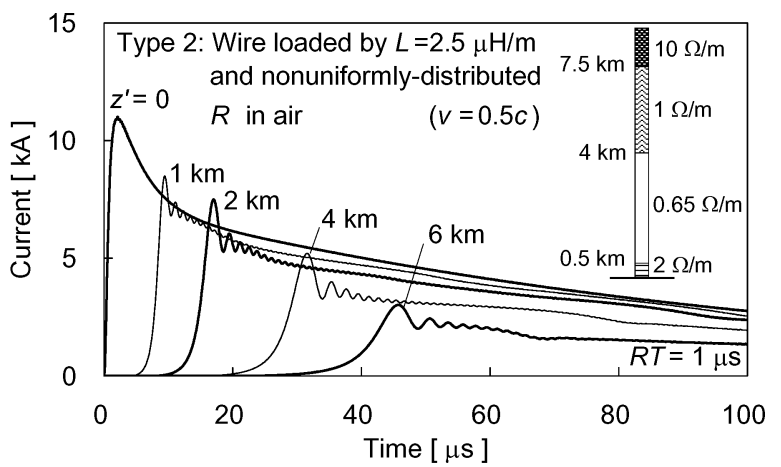

(a)

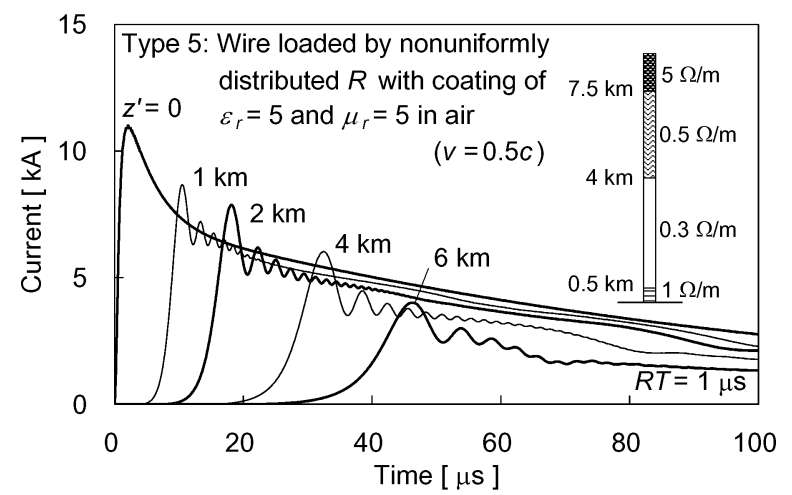

(b)

Fig. 5. Current waveforms at different heights calculated using the FDTD method for (a) type-2 model and (b) type-5 model shown in Fig. 1(b) and (e) but with nonuniformly distributed series resistance. For the type- 2 model, the nonuniformly distributed series resistance is $R=2 \Omega / \mathrm{m}$ for $z^{\prime}=0-0.5 \mathrm{~km}$, $0.65 \Omega / \mathrm{m}$ for $z^{\prime}=0.5-4 \mathrm{~km}, 1 \Omega / \mathrm{m}$ for $z^{\prime}=4-7.5 \mathrm{~km}$, and $10 \Omega / \mathrm{m}$ for $z^{\prime}>$ $7.5 \mathrm{~km}$. For the type-5 model, the relative permittivity and permeability of 10 -m-radius cylinder containing the vertical wire are $\varepsilon_{r}=5$ and $\mu_{r}=5$, and the nonuniformly distributed series resistance is $R=1 \Omega / \mathrm{m}$ for $z^{\prime}=0-0.5 \mathrm{~km}$, $0.3 \Omega / \mathrm{m}$ for $z^{\prime}=0.5-4 \mathrm{~km}, 0.5 \Omega / \mathrm{m}$ for $z^{\prime}=4-7.5 \mathrm{~km}$, and $5 \Omega / \mathrm{m}$ for $z^{\prime}>$ $7.5 \mathrm{~km}$.

for $z^{\prime}=4$ to $7.5 \mathrm{~km}$, and $5 \Omega / \mathrm{m}$ for $z^{\prime}>7.5 \mathrm{~km}$. The specified resistance profiles with relatively high resistance within the bottom $0.5 \mathrm{~km}$ appear to be consistent with observed light profiles along both natural subsequent return-stroke channels [33] and rocket-triggered lightning channels [34], showing that the light intensity decays significantly with height near ground. The reason for assuming the relatively high channel resistance above $7.5 \mathrm{~km}$ is to diminish the current above $7.5 \mathrm{~km}$. Calculations are also presented for the type-2 model and 7.5-km-long channel whose upper end is connected directly to the absorbing boundary, with the same resistance profile below height $7.5 \mathrm{~km}$ as for the 30-km-long channel.

Fig. 5(a) and (b) shows FDTD-calculated distributions of current along the lightning channel for type- 2 and type- 5 models. Comparisons of Figs. 5(a) and 2(b), and Figs. 5(b) and 2(e) show that current waves attenuated more significantly below $z^{\prime}=1 \mathrm{~km}$ and above $z^{\prime}=4 \mathrm{~km}$. The current propagation speed is not significantly influenced by the distributed resistance, and remains at about $v=0.5 c$.

Fig. 6(a)-(c) shows FDTD-calculated vertical electric field waveforms at $d=50 \mathrm{~m}, 5 \mathrm{~km}$, and $50 \mathrm{~km}$ for type- 2 and type-5 models. Fig. 6(d) shows FDTD-calculated waveforms 


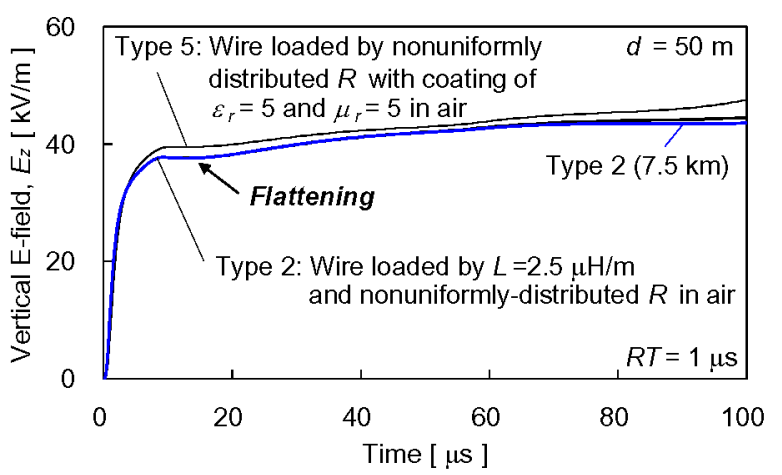

(a)

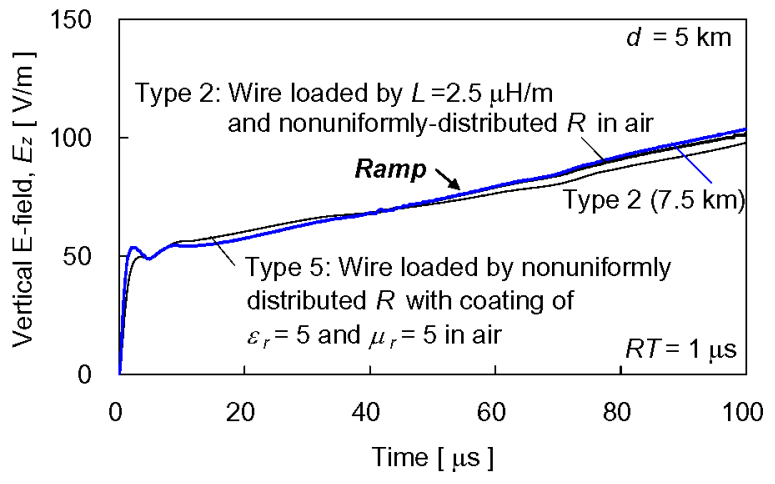

(b)

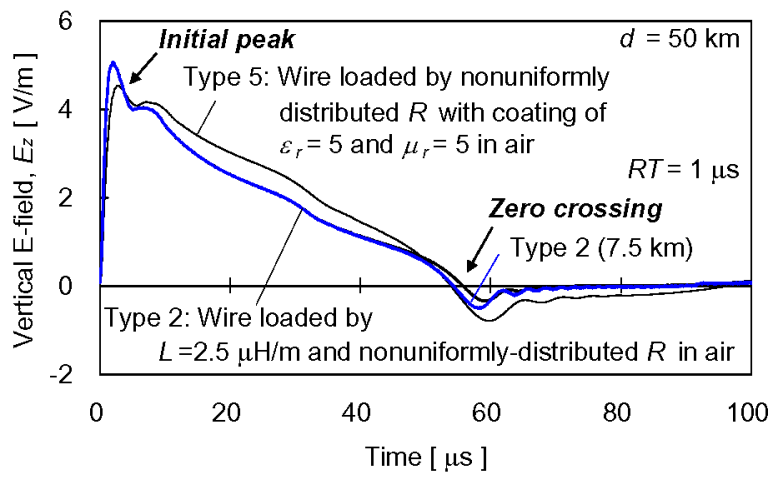

(c)

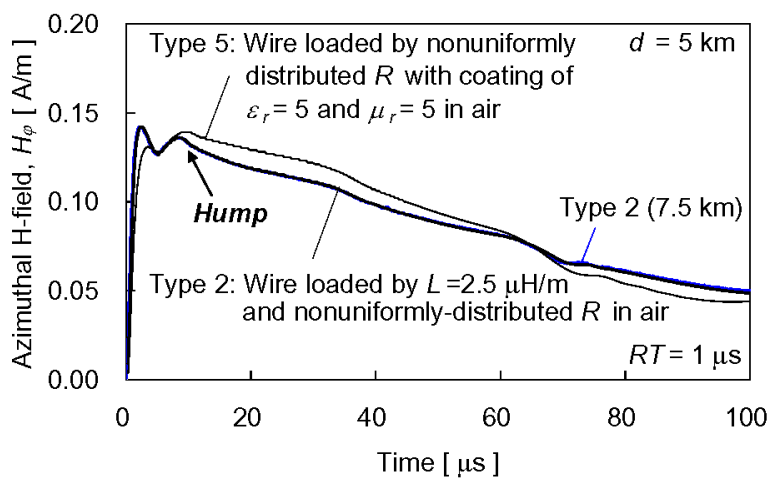

(d)

Fig. 6. Vertical electric field waveforms at (a) $d=50 \mathrm{~m}$, (b) $d=5 \mathrm{~km}$, and (c) $d=50 \mathrm{~km}$, and (d) azimuthal magnetic field waveforms at $d=5 \mathrm{~km}$, calculated using the FDTD method for type- 2 and type- 5 models of length $30 \mathrm{~km}$ shown in Fig. 1(b) and (e) but with nonuniformly distributed resistance. Also shown are waveforms calculated for the type-2 model with nonuniformly distributed resistance and 7.5-km-long channel whose upper end is connected directly to the absorbing boundary.

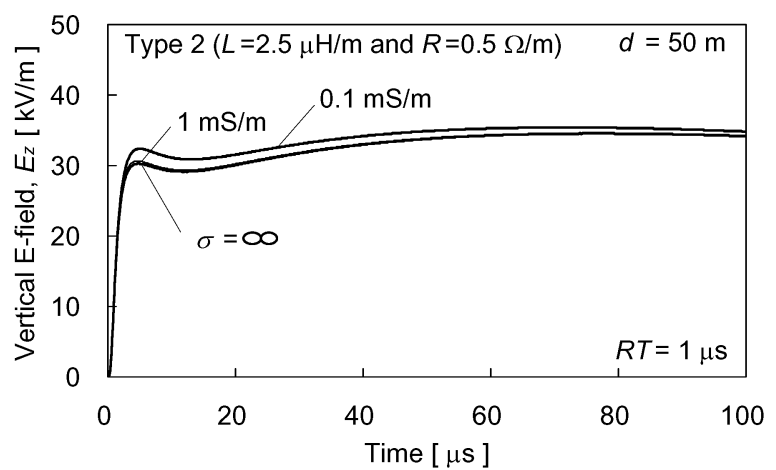

(a)

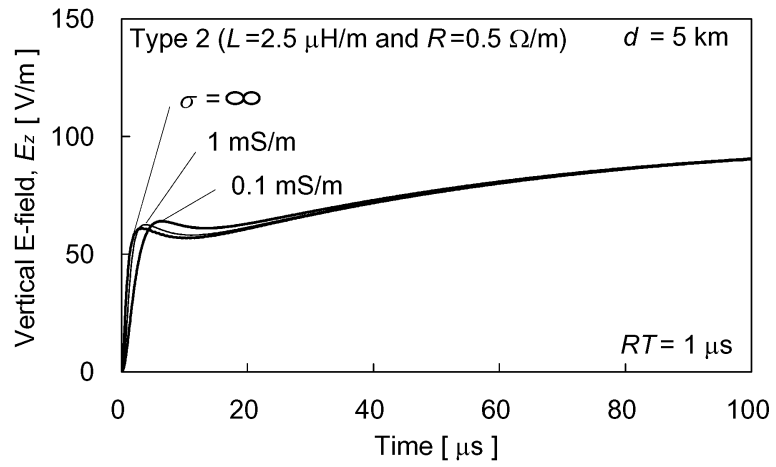

(b)

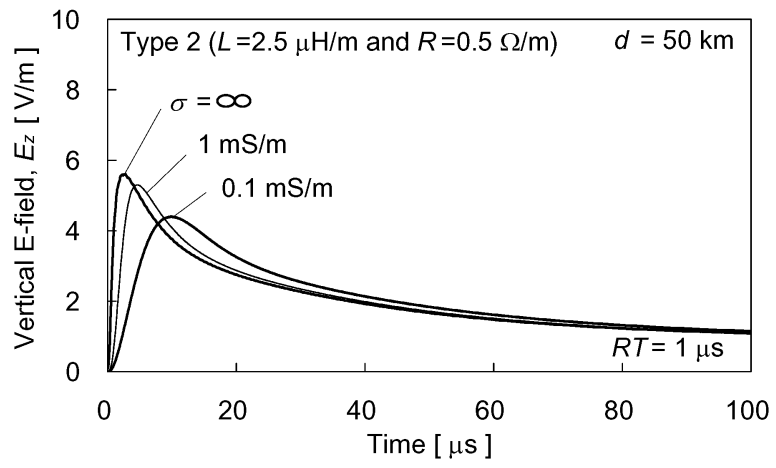

(c)

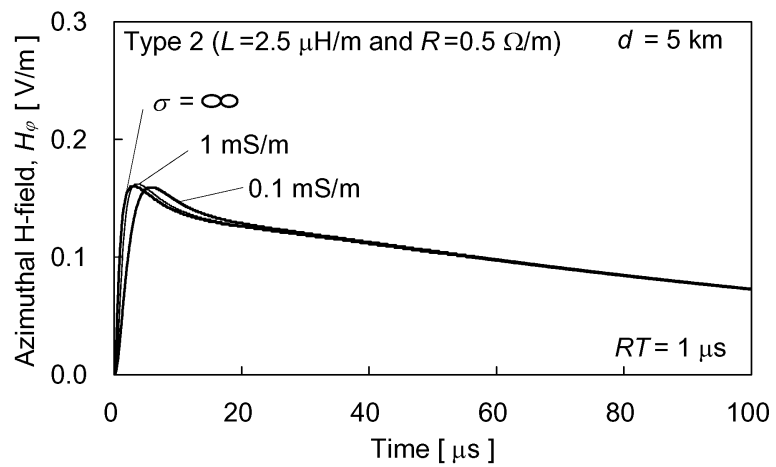

(d)

Fig. 7. Vertical electric field waveforms at (a) $d=50 \mathrm{~m}$, (b) $d=5 \mathrm{~km}$, and (c) $d=50 \mathrm{~km}$, and (d) azimuthal magnetic field waveforms at $d=5 \mathrm{~km}$, calculated using the FDTD method for the type-2 representation of the lightning return-stroke channel shown in Fig. 1(b). The fields are presented for $\sigma=\infty$, $1 \mathrm{mS} / \mathrm{m}$, and $0.1 \mathrm{mS} / \mathrm{m}$. 
TABLE I

INFLUENCES OF GROUND CONDUCTIVITY $\sigma$ ON THE INITIAL PEAK AND 10\%-90\% RISE TIME OF THE VERTICAL ELECTRIC FIELD AT DisTANCES RANGING FROM $d=50 \mathrm{~m}$ TO $50 \mathrm{~km}$

\begin{tabular}{l|c|c|c|c}
\hline \multirow{2}{*}{ Parameter } & \multirow{2}{*}{$\sigma, \mathrm{mS} / \mathrm{m}$} & \multicolumn{3}{|c}{ Distance } \\
\cline { 3 - 5 } & & $5 \mathrm{~km}$ & $10 \mathrm{~km}$ & $50 \mathrm{~km}$ \\
\hline Peak & 1 & 2 & 0 & -5 \\
\cline { 2 - 5 } decrease, $\%$ & 0.1 & 5 & -4 & -20 \\
\hline Risetime & 1 & 0.3 & 0.6 & 1.2 \\
\cline { 2 - 5 } increase, $\mu \mathrm{s}$ & 0.1 & 1.7 & 2.2 & 4.3 \\
\hline
\end{tabular}

Peak decrease (increase at $5 \mathrm{~km}$ ) and rise time increase given in the table are relative to the corresponding value for $\sigma=\infty$. Rise time is $1 \mu$ s for $\sigma=\infty$.

of azimuthal magnetic field at $d=5 \mathrm{~km}$. It is clear from Fig. 6 that all five features are reproduced by both type- 2 and type5 models with nonuniformly distributed series resistance. It is also clear that the contribution of the relatively high resistance channel section above $7.5 \mathrm{~km}$ on electric and magnetic field waveforms is not significant, since the magnitude of the current propagating along the upper channel section is small.

\section{INFLUENCE OF GROUND CONDUCTIVITY ON $E_{z}$ AND $H_{\varphi}$}

In the preceding sections, ground was assumed to be perfectly conducting. In this section, we investigate the influence of finite ground conductivity on lightning-produced electromagnetic field waveforms.

Fig. 7 illustrates the effect of lossy ground on vertical electric and azimuthal magnetic field waveforms calculated using the FDTD method for the type- 2 representation of the lightning return-stroke channel $(L=2.5 \mu \mathrm{H} / \mathrm{m}$ and $R=0.5 \Omega / \mathrm{m})$. Table I summarizes the initial peak and rise time of the vertical electric field at distances ranging from $d=50 \mathrm{~m}$ to $50 \mathrm{~km}$ for two values of ground conductivity, $\sigma=0.1$ and $1 \mathrm{mS} / \mathrm{m}$, relative to the case of $\sigma=\infty$. Note that the same lossy ground is considered both in calculating the channel current distribution and in computing fields. It is, however, common practice to independently set characteristics of ground in specifying current distribution and in computing fields [35]. Computed fields are presented for $\sigma=$ $\infty, 1 \mathrm{mS} / \mathrm{m}$, or $0.1 \mathrm{mS} / \mathrm{m}$, and the relative permittivity is set to $\epsilon_{r}=10$. It follows from Fig. 7 and Table I that the influence of ground conductivity as low as $0.1 \mathrm{mS} / \mathrm{m}$ on vertical electric and azimuthal magnetic fields within about $d=5 \mathrm{~km}$ is not significant. The initial peak of the vertical electric field at $d=$ $50 \mathrm{~km}$ for $\sigma=0.1 \mathrm{mS} / \mathrm{m}$ is $20 \%$ smaller than that for $\sigma=$ $\infty$. The $10 \%-90 \%$ rise time is $5 \mu$ s at $d=50 \mathrm{~km}$ for $\sigma=$ $0.1 \mathrm{mS} / \mathrm{m}$ versus $1 \mu \mathrm{s}$ for $\sigma=\infty$. Similar propagation effects were observed when the engineering transmission-line model with $v=0.5 c$ was used.

\section{SUMMARY}

We have compared current distributions along a vertical lightning channel excited at its bottom by a lumped current source above flat ground and electromagnetic field waveforms at different distances, calculated for different lightning return-stroke electromagnetic models. The channel representations considered include a vertical, perfectly conducting wire surrounded by air (type 1), a vertical wire loaded by additional distributed series inductance $L=2.5 \mu \mathrm{H} / \mathrm{m}$ and distributed series resistance $R=0.5 \Omega / \mathrm{m}$ (type 2 ) in air, a vertical, perfectly conducting wire embedded in dielectric of $\varepsilon_{r}=4$ that occupies the entire half space (type 3 ), a vertical, perfectly conducting wire embedded in a 10 -m-radius dielectric cylinder of $\varepsilon_{r}=400$ surrounded by air (type 4), and a vertical wire embedded in a 10-m-radius cylinder of $\varepsilon_{r}=5$ and $\mu_{r}=5$ surrounded by air (type 5). For the type- 1 representation, the speed of a current wave propagating along the vertical lightning channel is essentially equal to the speed of light $v=c$. For type-2, type-3, and type- 5 representations, $v=$ $0.5 c$, and for the type-4 representation, $v=0.7 c$.

Models of types 2 and 5 reproduce the maximum number of characteristic features of electric and magnetic field waveforms measured at distances ranging from 1 to $200 \mathrm{~km}$ from natural lightning and at distances of tens to hundreds of meters from rocket-triggered lightning. Modifications of type-2 and type5 models with height-varying distributed resistance (relatively high within the bottom $0.5 \mathrm{~km}$ and beyond $7.5 \mathrm{~km}$ above ground) can reproduce all of the five features.

The influence of ground conductivity as low as $0.1 \mathrm{mS} / \mathrm{m}$ on vertical electric and azimuthal magnetic fields within about $d=$ $5 \mathrm{~km}$ is not significant. The initial peak of the vertical electric field at $d=50 \mathrm{~km}$ for $\sigma=0.1 \mathrm{mS} / \mathrm{m}$ is $20 \%$ smaller than that for $\sigma=\infty$. The $10 \%-90 \%$ rise time at $d=50 \mathrm{~km}$ is $5 \mu$ s for $\sigma=0.1 \mathrm{mS} / \mathrm{m}$, while it is $1 \mu \mathrm{s}$ for $\sigma=\infty$.

\section{REFERENCES}

[1] V. A. Rakov and M. A. Uman, "Review and evaluation of lightning return stroke models including some aspects of their application," IEEE Trans. Electromagn. Compat., vol. 40, no. 4, pp. 403-426, Nov. 1998.

[2] M. N. Plooster, "Numerical model of the return stroke of the lightning discharge," Phys. Fluids, vol. 14, pp. 2124-2133, 1971.

[3] Y. Baba and V. A. Rakov, "Electromagnetic models of the lightning return stroke," J. Geophys. Res., vol. 112, no. D04102, 17 pp. Feb. 2007. DOI: 10.1029/2006JD007222.

[4] S. Visacro and A. De Conti, "A distributed-circuit return-stroke model allowing time and height parameter variation to match lightning electromagnetic field waveform signatures," Geophys. Res. Lett., vol. 32, no. L23805, pp. L23805-1-L23805-5, Dec. 2005. DOI:10.1029/2005GL024336.

[5] V. Cooray and N. Theethayi, "Pulse propagation along transmission lines in the presence of corona and their implication to lightning return strokes," IEEE Trans. Antennas Propag., vol. 56, no. 7, pp. 1948-1959, Jul. 2008.

[6] C. A. Nucci, G. Diendorfer, M. A. Uman, F. Rachidi, M. Ianoz, and C. Mazzetti, "Lightning return stroke current models with specified channel-base current: A review and comparison," J. Geophys. Res., vol. 95, no. D12, pp. 20395-20408, Nov. 1990.

[7] R. F. Harrington, Field Computation by Moment Methods. New York: Macmillan, 1968.

[8] E. K. Miller, A. J. Poggio, and G. J. Burke, "An integro-differential equation technique for the time-domain analysis of thin wire structures," J. Comput. Phys., vol. 12, pp. 24-48, 1973.

[9] K. S. Yee, "Numerical solution of initial boundary value problems involving Maxwell's equations in isotropic media," IEEE Trans. Antennas Propag., vol. 14, no. 3, pp. 302-307, Mar. 1966.

[10] Y. Baba and V. A. Rakov, "Applications of electromagnetic models of the lightning return stroke," IEEE Trans. Power Del., vol. 23, no. 2, pp. 800-811, Apr. 2008.

[11] A. S. Podgorski and J. A. Landt, "Three dimensional time domain modelling of lightning," IEEE Trans. Power Del., vol. 2, no. 3, pp. 931-938, Jul. 1987

[12] S. Kato, T. Narita, T. Yamada, and E. Zaima, "Simulation of electromagnetic field in lightning to tall tower," presented at the 11th Int. Symp. High Voltage Eng., London, U.K., no. 467, Aug. 1999.

[13] R. Moini, B. Kordi, G. Z. Rafi, and V. A. Rakov, "A new lightning return stroke model based on antenna theory," J. Geophys. Res., vol. 105, no. D24, pp. 29 693-29 702, Dec. 2000. 
[14] S. Kato, T. Takinami, T. Hirai, and S. Okabe, "A study of lightning channel model in numerical electromagnetic field computation," (in Japanese), presented at the 2001 IEEJ Nat. Conv., Nagoya, Japan, Mar. 2009.

[15] S. Miyazaki and M. Ishii, "Reproduction of electromagnetic fields associated with lightning return stroke to a high structure using FDTD method," (in Japanese), in Proc. 2004 IEEJ Nat. Conv., Kanagawa, Japan, Mar. 2004, no. 7-065, p. 98.

[16] S. Bonyadi-Ram, R. Moini, S. H. H. Sadeghi, and V. A. Rakov, "Incorporation of distributed capacitive loads in the antenna theory model of lightning return stroke," in Proc. 16th Int. Zurich Symp. Electromagn. Compat., Zurich, Switzerland, Mar. 2005, pp. 213-218.

[17] V. A. Rakov and A. A. Dulzon, "Calculated electromagnetic fields of lightning return stroke," Tekh. Elektrodinam., no. 1, pp. 87-89, 1987 (in Russian).

[18] V. A. Rakov, "Lightning return stroke speed," J. Lightning Res., vol. 1, pp. 80-89, 2007.

[19] B. N. Gorin and A. V. Shkilev, "Measurements of lightning currents at the Ostankino tower," Electrichestrvo, no. 8, pp. 64-65, 1984 (in Russian).

[20] Y. Baba and V. A. Rakov, "On the mechanism of attenuation of current waves propagating along a vertical perfectly conducting wire above ground: Application to lightning," IEEE Trans. Electromagn. Compat., vol. 47, no. 3, pp. 521-532, Aug. 2005.

[21] V. A. Rakov, "Some inferences on the propagation mechanisms of dart leaders and return strokes," J. Geophys. Res., vol. 103, no. D2, pp. 18791887, 1998

[22] S. Bonyadi-Ram, R. Moini, S. H. H. Sadeghi, and V. A. Rakov, "On representation of lightning return stroke as a lossy monopole antenna with inductive loading," IEEE Trans. Electromagn. Compat., vol. 50, no. 1, pp. 118-127, Feb. 2008.

[23] V. P. Idone and R. E. Orville, "Lightning return stroke velocities in the thunderstorm research international program (TRIP)," J. Geophys. Res., vol. 87, pp. 4903-4915, 1982.

[24] R. J. Fisher, G. H. Shnetzer, R. Thottappillil, V. A. Rakov, M. A. Uman, and J. D. Goldberg, "Parameters of triggered-lightning flashes in Florida and Alabama," J. Geophys. Res., vol. 72, pp. 22 887-22 902, Dec. 1993.

[25] Y. Taniguchi, Y. Baba, N. Nagaoka, and A. Ametani, "Representation of an arbitrary-radius wire for FDTD calculations in the 2-D cylindrical coordinate system," IEEE Trans. Electromagn. Compat., vol. 50, no. 4, pp. 1014-1018, Nov. 2008.

[26] R. Thottappillil, J. Schoene, and M. A. Uman, "Return stroke transmission line model for stroke speed near and equal that of light," Geophys. Res. Lett., vol. 28, no. 18, pp. 3593-3596, Sep. 2001.

[27] Z. P. Liao, H. L. Wong, B.-P. Yang, and Y.-F. Yuan, "A transmitting boundary for transient wave analysis," Sci. Sinica, vol. A27, no. 10, pp. 1063-1076, 1984

[28] Y. T. Lin, M. A. Uman, J. A. Tiller, R. D. Brantley, W. H. Beasley, E. P. Krider, and C. D. Weidman, "Characterization of lightning return stroke electric and magnetic fields from simultaneous two-station measurements," J. Geophys. Res., vol. 84, pp. 6307-6314, 1979.

[29] D. E. Crawford, V. A. Rakov, M. A. Uman, G. H. Schnetzer, K. J. Rambo, M. V. Stapleton, and R. J. Fisher, "The close lightning electromagnetic environment: Dart-leader electric field change versus distance," J. Geophys. Res, vol. 106, no. D14, pp. 14909-14 917, Jul. 2001.

[30] Y. Baba, S. Miyazaki, and M. Ishii, "Reproduction of lightning electromagnetic field waveforms by engineering model of return stroke," IEEE Trans. Electromagn. Compat., vol. 46, no. 1, pp. 130-133, Feb. 2004.

[31] R. Thottappillil, M. A. Uman, and G. Diendorfer, "Influence of channel base current and varying return stroke speed on the calculated fields of three important return stroke models," presented at the Int. Conf. Lightning Static Electr., Cocoa Beach, FL, Apr. 1991.
[32] V. Cooray, V. A. Rakov, F. Rachidi, R. Montano, and C. A. Nucci, "On the relationship between the signature of close electric field and the equivalent corona current in lightning return stroke models," IEEE Trans. Electromagn. Compat., vol. 50, no. 4, pp. 921-927, Nov. 2008.

[33] D. M. Jordan, V. A. Rakov, W. H. Beasley, and M. A. Uman, "Luminosity characteristics of dart leaders and return strokes in natural lightning," $J$. Geophys. Res., vol. 102, no. D18, pp. 22 025-22 032, Sep. 1997.

[34] R. C. Olsen III, D. M. Jordan, V. A. Rakov, M. A. Uman, and N. Grimes, "Observed one-dimensional return stroke propagation speeds in the bottom $170 \mathrm{~m}$ of a rocket-triggered lightning channel," Geophys. Res. Lett., vol. 31, no. L16107, pp. L16107-1-L16107-4, Aug. 2004. DOI: 10.1029/2004GL02187.

[35] Y. Baba and V. A. Rakov, "Electromagnetic fields at the top of a tal building associated with nearby lightning return strokes," IEEE Trans. Electromagn. Compat., vol. 49, no. 3, pp. 632-643, Aug. 2007.

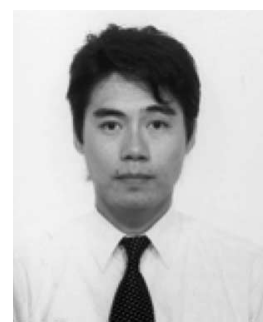

Yoshihiro Baba (S'95-M'99) received the B.S., M.S., and Ph.D. degrees from the University of Tokyo, Tokyo, Japan, in 1994, 1996, and 1999, respectively.

$\mathrm{He}$ is currently an Associate Professor in the Department of Electrical Engineering, Doshisha University, Kyoto, Japan. From April 2003 to August 2004, he was a Visiting Scholar at the University of Florida, on sabbatical leave from Doshisha University. He is the author or coauthor of more than 40 papers published in reviewed journals.

Dr. Baba is a member of the American Geophysical Union and the Institute of Engineering and Technology.

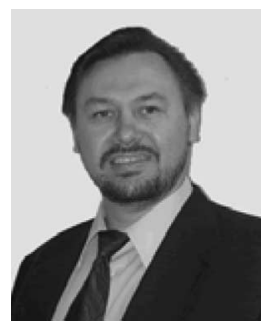

Vladimir A. Rakov (SM'96-F'03) received the M.S. and Ph.D. degrees in electrical engineering from Tomsk Polytechnical University (Tomsk Polytechnic), Tomsk, Russia, in 1977 and 1983, respectively.

From 1977 to 1979, he was an Assistant Professor of electrical engineering at Tomsk Polytechnic. From 1978, he was engaged in lightning research at the High Voltage Research Institute (a division of Tomsk Polytechnic), where he was the Director of the Lightning Research Laboratory from 1984 to 1994 . He is currently a Professor in the Department of Electrical and Computer Engineering, University of Florida, Gainesville, where he is also a Co-Director of the International Center for Lightning Research and Testing (ICLRT) and Chair of Electromagnetics and Energy Systems Division. He is the lead author of one book Lightning: Physics and Effects, and has authored or coauthored more than 500 other publications on various aspects of lightning with over 160 papers being published in reviewed journals. He is an Editor or an Associate Editor of four technical journals

Dr. Rakov is the Chairman of the Technical Committee on Lightning of the Biennial International Zurich Symposium on Electromagnetic Compatibility, a Co-Chairman of the International Union of Radio Science (URSI) Working Group (WG) E.4 "Lightning Discharges and Related Phenomena," and the Convener of the International Council on Large Electric Systems (CIGRE) WG C4-407 "Lightning Parameters for Engineering Applications." He is a Fellow of the American Meteorological Society (AMS) and the Institution of Engineering and Technology (formerly IEE). 